Я. С. Камышникова

\title{
СИНТАКСИЧЕСКИЕ ОСОБЕННОСТИ РЕКЛАМНОГО СЛОГАНА В АНГЛИЙСКОМ ЯЗЫКЕ И ЕГО ПЕРЕВОД НА РУССКИЙ
}

Камишнікова Я. С. Синтаксичні особливості рекламного салогана в англійській мові та його переклад на російську.

Статтю присвячено вивченню основних синтаксичних прийомів створення рекламного слогану в англійській мові. Виокремлено такі прийоми, як еліптичні конструкції, синтаксичний повтор, паралелізм, парцеляція та інші. Проаналізовано переклади деяких рекламних слоганів на російську мову 3 позиції збереження синтаксичної структури оригіналу.

Ключові слова: слоган, синтаксичний прийом, еліптичні конструкції, синтаксичний повтор, паралелізм, парцеляція. 
Камышникова Я. С. Синтаксические особенности рекламного слогана в английском языке и его перевод на русский.

Статья посвящена изучению основных синтаксических приемов создания рекламного слогана в английском языке. Определены такие приемы, как эллиптические конструкции, синтаксический повтор, параллелизм, парцелляция и другие. Проанализированы переводы некоторых рекламных слоганов на русский язык с позиции сохранения синтаксической структуры оригинала.

Ключевые слова: слоган, синтаксический прием, эллиптические конструкции, синтаксический повтор, параллелизм, парцелляция.

Kamyshnikova Y. S. Syntactic features of advertising slogan in the English language and its translation into Russian.

The main syntactic techniques of slogan making are studied in the article. Such techniques as elliptical constructions, syntactic repetition, parallelism, parceling are defined. The translations of some slogans are analysed, due to their syntactic structure and its preservation in the translation.

Key words: slogan, syntactic technique, elliptical constructions, syntactic repetition, parallelism, parceling.

На сегодняшний день сложно представить сферу человеческих отношений без такого социального явления, как реклама. Реклама не только организует и регулирует некоторые процессы взаимодействия людей, но и напрямую или косвенно влияет на их социокультурное состояние, на образ мышления, формирует их ценностные предпочтения и т. д. Также, реклама способна определить ту речевую атмосферу, в которой живет общество на данном этапе своего развития.

Данная проблема кажется актуальной ввиду быстрого и стремительного развития информационных технологий, экономических отношений между различными странами. Товары, услуги и торговые марки быстро выходят за границы той или иной страны, завоевывая международный рынок. Важнейшей задачей современных производителей является максимально скорое привлечение интереса населения к товару посредством эффективной рекламы. Слоган занимает одно из центральных мест в структуре рекламного текста. Вместе с рекламируемым собственным именем он выражает основной смысл рекламной концепции. Нередко весь рекламный текст состоит из рекламируемого собственного имени и сопровождающего его слогана. Не смотря на большое количество работ, посвященных анализу языка рекламы, постоянно развивающийся характер рекламной индустрии требует новых подходов в анализе рекламного текста и слогана в частности.

Современная наука рассматривает значимость рекламы в () Я. С. Камышникова, 2014. 
коммуникативном пространстве как одного из наиболее мощных рычагов формирования и моделирования общественного мнения. Слоган, вне зависимости от типа рекламного текста и канала коммуникации, несет в себе если не основную, то достаточно серьезную информационную и, в особенности, эмоциональную нагрузку, чтобы представлять особый интерес в качестве объекта исследования. Слоган определяется как «рекламный словесный эквивалент логотипа фирмы. В печатном объявлении он обычно появляется рядом с графическим знаком фирмы или названием предприятия, сразу же под ними или в конце рекламного объявления. В рекламном лозунге отражена и сконцентрирована позиция рекламируемой фирмы, он делает ее привлекательной для клиентов и узнаваемой» [3, с. 29]. По определению А. Ульянова «Слоган рекламный лозунг: четкая, ясная и сжатая формулировка рекламной идеи, которая легко воспринимается и запоминается» [4, с. 92]. Самой главной характеристикой слогана, пожалуй, является то, что он отражает сущность, философию фирмы, ее корпоративную политику в различных областях. Как уже отмечалось, чаще всего слоган стоит в конце рекламного сообщения, рядом с именем рекламодателя или рекламируемой товарной марки - бренда. Эта позиция обусловлена резюмирующей ролью слогана: краткое, выраженное одним предложением содержание рекламной кампании. Он подводит итог всему, сказанному в рекламе. Кроме того, слоган служит связующим звеном между многими отдельными сообщениями, входящими в общую рекламную кампанию. Именно поэтому традиционное положение слогана - в конце рекламного сообщения. Слоган отражает сущность, философию фирмы, ее корпоративную политику в различных областях [3, с. 30].

Целью данной работы является обозначение и выявление специфики языка рекламных слоганов и определение некоторых проблем, связанных с их переводом с английского языка на русский. Мы попытаемся установить какие именно стилистические приемы используются для того, чтобы создать привлекающий внимание, запоминающийся и эффективный текст.

Благодаря силе формы, месту расположения, а также стилистическим особенностям, слоган воздействует как на сознание, так и на подсознание людей, взаимодействуя с уже имеющимися знаниями и набором эмоциональных реакций адресата. Необходимому эффекту способствует тщательный подбор стилистических, 
грамматических, лексических и синтаксических средств слоганов. К синтаксическим средствам относятся эллипсис, повтор, большое количество побудительных и восклицательных предложений и многие другие приемы. При переводе этих приемов на русский язык, какие-то тенденции сохраняются и несут такую же эмоциональную нагрузку, как и в исходном языке, какие-то конструкции заменяются на равнозначные по своей семантике, стилистике и эмоциональному восприятию.

Одной из наиболее распространенных синтаксических моделей слогана, характерной и для разговорной речи, является эллипсис. Эллиптическими являются предложения, один или оба главных членов которых формально не представлены и присутствуют лишь в синтаксическом окружении или имплицируются речевой ситуацией. Эллипсис позволяет выделить наиболее важные элементы в высказывании, когда подразумеваемый элемент может быть легко восполнен из контекста. Эллипсис подлежащего и части сказуемого (личной формы глагола) широко распространен в рекламных слоганах. Это связано с тем, что рекламный текст стремится по своему стилю к разговорной речи. Причем в русском языке подобная конструкция не всегда эффективна и, следовательно, не всегда соблюдена. Keеps уои informed (Grundic) - Он всегда держит вас в курсе. Vitalizes body and mind. (Red Bull energy drink) - Оживляет тело и разум. Creating a Higher Standard. (Cadillac cars) - Создавая более высокие стандарты. Accelerating the future (Infinity) - Ускоряя будущее. Иногда наблюдается полное отсутствие главных членов предложения, причем данный прием эффективен и при переводе на русский язык. В данном случае достигается эффект краткости, лаконичности и смысловой глубины. Perfect to you (Wella) - Лучшее для ваших волос. Saturn. Like always. Like never before. (Saturn Cars) Сатурн. Как всегда. Как никогда раньше. A style for every story. (Levi's Jeans) - Стильные для любого случая. Подобные структурные опущения прагматически указывают на нечто неявно выраженное, предполагают осмысление, результаты которого смогут побудить адресата к действию.

Повтор также является сильным синтаксическим средством языка рекламы, а слогана в особенности. Повторяться могут отдельные слова, словосочетания и целые предложения. How refreshing! How Heineken! (Heineken beer); The Great Tea from Great Britain (Sir Winston Tea) - Великий чай из Великобритании. В данном 
случае в переводе сохраняется как повтор, так и лексическое значение слова Great - великий. More defined. More conditioned. More beautiful lashes. (Estee Lauder) - Более выразительные, более разделенные, более прекраснье ресницьь. They said it couldn't be done. It couldn't! (Volkswagen) - Они говорили, это невозможно сделать. Неужели! В последнем случае наблюдаем повтор слова can в двух разных значениях. Так, в первом предложении They said it couldn't be done отрицательная форма глагола can употребляется в значении невозможно, не в состоянии, в то время как вторая часть слогана It couldn't! не повторяется в этом же значении, а выражает сомнение, неуверенность по поводу вышесказанного. Невозможное оказывается возможным и воплощено в автомобиле Volkswagen.

С целью придания слогану определенного ритма, создатели рекламы прибегают к такому приему, как параллелизм. Под параллельными конструкциями понимают такие предложения, в которых отдельные их части построены однотипно. Параллельные синтаксические конструкции (тождественное или сходное расположение элементов речи в смежных частях текста) чаще всего фигурируют в комплексе с экспрессивными фонетическими стилистическими приемами, свойственными стихосложению и позволяющими создавать краткие, запоминающиеся и уникальные рекламные тексты. Частое сочетание параллелизма с анафорой (т.е. употребление лексически тождественных компонентов в начале предложения или фразы) служит одной цели - удержать, закрепить в памяти читателя настойчиво подчеркиваемый повторением элемент. How refreshing! How Heineken! (Heineken beer) - Kaк свежо! Kaк Heineken!; Drink responsibly, drive responsibly, live responsibly (Miller bеег) - Пей ответственно, води ответственно, живи ответственно. My card. My life. (American Express) - Моя карта. Моя жизнь. Эффективность приема проявляется в органической связи всех компонентов текста. Каждый из этих компонентов важен не так сам по себе, как часть целого, несущая максимально смысловую нагрузку концентрированно выражающая это целое, а оно, в свою очередь, особым образом преломляется в части.

Сильным синтаксическим приемом является парцелляция. Под парцелляцией понимают «такое членение предложений, при котором содержание высказывания реализуется не в одной, а в двух или нескольких интонационно-смысловых речевых единицах, следующих одна за другой после разделительной паузы» [5, с. 271]. Показателем 
синтаксического разрыва является точка (или другой знак конца предложения), что приводит к увеличению частотности употребления точки, а при зрительном восприятии текста - к его интонированию. Парцеллированные конструкции характерны для побудительных слоганов. Better ideas. Driven by уои (Ford) - Лучшие идеи. За рулем которых Bbl; Ready, set, go! (Maybelline) - Ha cmapm! Внимание! Maрu! В рекламных текстах этот прием встречается довольно часто, так как при его использовании создается определенная ритмика и акцентируется внимание на необходимой части высказывания. Примечательно, что в переводе на русский язык подобный прием также эффективен и экспрессивен, что позволяет говорить о том, что парцелляция сохраняется и в языке перевода.

Как уже отмечалось выше, рекламный слоган должен нести определенную долю эмоциональности, яркости. Этому эффекту способствуют побудительные конструкции и риторические вопросы. Это связано с тем, что как восклицательный, так и вопросительный знак хорошо выделяется графически, привлекая внимание к тексту и вызывая определенный интерес. Is it live, or is it Memorex? (Memorex)Это прямая трансляция или это Meтorex?; It's Miller time! (Miller) Пришло время Миллер! ; Don't dream it. Drive it! (Jaguar cars) Хватит мечтать. Пора еxamb!; Isn't it time for a real car? (Buick cars) - Не пришло ли время купить настоящую машину? Как видим, переведенные слоганы такие же эмоциональные и экспрессивные как и оригинальные. Это помогает передать необходимую эмоциональную окраску в языке перевода.

Таким образом, слоган занимает одно из центральных мест в структуре рекламного текста. Он выражает основной смысл рекламной концепции. Стремясь мысленно сократить дистанцию между адресатом и адресантом, и, соответственно, повысить уровень доверия к сообщению, составители рекламных текстов приближают их к стилю разговорной речи. Это достигается использованием соответствующих синтаксических средств. При создании рекламных слоганов широкое распространение получили эллиптические конструкции, синтаксический повтор одного или нескольких элементов, параллелизм, парцелляция, побудительные конструкции, риторические вопросы и другие. Выбор этих средств зависит от особенностей предполагаемой целевой аудитории, типа рекламируемого продукта и концепции самой компании. При переводе рекламных слоганов, зачастую удается сохранить синтаксический рисунок оригинала с целью вызвать 
предполагаемую эмоциональную реакцию. Если же это сделать не возможно, подбираются эквивалентные синтаксические средства, близкие к оригиналу по своей стилистике. Задача переводчика использовать все знания теоретических основ перевода для передачи коммуникативной функции оригинала, учитывать этнические и культурные особенности реципиента. Это требует общей эрудиции, глубокого знания как языка оригинала, так и языка, на который переводится рекламный текст. Слоган, являясь порождением массовой культуры, претерпевает изменения. Происходит его дифференциация по социальным, возрастным группам и все большая индивидуализация адресата. Привлечение все новых языковых способов для создания рекламы усиливает экспрессивность и эмоциональность ее языка. Это позволяет говорить о перспективах дальнейшего изучения развития слогана как лингвистического явления.

\section{Литература}

1. Добросклонская Т. Г. Вопросы изучения медиатекстов. Опыт исследования современной английской медиаречи : [монография] / Т. Г. Добросклонская - М. : Едиториал, 2005. - 288 с.

2. Кромптон А. Мастерская рекламного текста / А. Кромптон - М. : Довгань, 1998. - 243 с.

3. Сердобинцева Е. Н. Структура и язык рекламных текстов : [учеб. пособие] / Е. Н. Сердобинцева - М. : Флинта : Наука, 2010. - 104 с.

4. Ульянов А. М. Словарь терминов по рекламе, маркетингу, Atl, Btl и PR / А. М. Ульянов - М., 2007. -590 с.

5. Словарь-справочник лингвистических терминов / под ред. Д. Э. Розенталя и М. А. Теленковой / Д. Э. Розенталь, М. А. Теленкова. - [2-е изд.]. - М. : Просвещение, 1976. $-544 \mathrm{c}$. 